Raynaud's disease. There is a history of eating rye-breal for a long period in this case, but I think the disease was a genuine case, dne, as liaynaud says, to "enormous exaggeration of the grey parts of the spinal cord which control the vaso-motor innervation." I It is unfortunate that the case only came under observation when the gangrene was established, as there was no opportunity afforded of testing the efficacy of the continuous current recommended so strongly by the describer of the disease.

Carlisle.

\section{A CASE OF CEREBRO-SPINAL MENINGITIS COMPLTCATED WITH EAR DISEASE; NECROPSY.}

\section{BY DR. P. C. LARSEN, OF COPENHAGLS.}

The patient, a girl seven vears old, was admitted into hospital on Feb. 1st, 1890. She was suddenly takrn ill on Jan. 25 th with rigors, fever, and vomiting, three or five times during the first twenty-four hours; she also complained of headache. Four or five days later she felt pains in the neck and back, her sleep was disturbed, she smacked her lips, was flushed, and kept her legs drawn up; there was a slight opisthotonos, and she cried often ; cerebration was rather slow. The bowels had for the last few days been loose. When admitted she answered rationally, but the cerebration was slow. She complained of hearlacbe, cried now and then, and smacked her lips. Her tongue was dry. Both pupils reacted well. There were no strabismus, otorrhœa, or episthotonos. Her legs were drawn up, and she felt pain when they were exteuded. Trousseau's sign was present. Temperature $395^{\circ}$; pulse 88 , irregular.Feb. 2nd : Morning temperature $39^{\circ}$, evening $395^{\circ}$; pulse 88. This morning she has been somewhat deaf in both ears. Sensorium dull. Urine without albumen.-3rd : Temperature $38^{\circ}-38.2^{\circ}$; pulse 83 . Pain in head and back; none in the neck. Squeamishness, giddiness; complains for the first time of earache on the right side; deafness changing; at times she only hears the voice when close to the ear; no pains around the ear. -8th : Temperature $37 \cdot 4^{\circ}-376^{\circ}$; pulse 84 . Deafness has been continual. The examination shows the meatus auditorius externus normal. The membrana tympani has lost its lustre; there is a deeply situated reddish blush over the whole membrane, while no part of its integument is injected, and there is no bulging either of the membrane as a whole or of any part of it; no swelling or pain in the surroundings. The perception of the tuning fork through the cranial bones is entirely lost. Temperature $373^{\circ}-37^{\circ} 5^{\circ}$; pulse 60 . Yesterday she complained of a sleeping sensation in the right arm, with temporary loss of power. This morning it seems quite paralysed; sensibility unimpaired. The right leo is also paralysed, yet she can move the foot and toes slightly, both actively and by reflexion. No distinct facial paralysis; still she moves the left side of the mouth better than the right. She is unsteady when sitting in bed. She talks in a jerky way and slowly. Sensorium seems free. -13 th : Temperature $37 \cdot 6^{\circ}-383^{\circ}$; pulse 60 . At 930 A.M. and at 1 P.M. yesterday she had clonic crannps of respectively one minute and $a$ half and three minutes and three-quarters duration. The whole right side of the body, except the face, was attacked. Sensorium remained free. She is now lively, and uses her right arm; complains of pain in the right leg and the back, and feels chilly. From Feb. 14th until March 4 th the temperature generally ranged between $37^{\circ}$ and $38^{\circ}$, occasionally rising in the evening to $39^{\circ}$. The pulse counted generally from 85 to 90 , rose once to 100 , and went down once to 72. She had much headache, but sensorium remained almost free. She felt very depressed in her mind, longing for home, and on March 4th she requested to be sent home, where she died on March 9th, having passed the last three days in an unconscious state with involuntary evacuations.

The necropsy was made in the hospital on March 11 th, whither the parents allowed the corpse to be brought. The dura mater was not yery much songested or thickened; at

1 On Local Asphyxia and Symmetrical Gangrene of the Extremities by Maurice Laynaud; vol. cxxi. of New Sydenham Society, p. 182. some few places it adhered indissolubly to the pia mater and the brain-namely, (1) at the highest point of the gyrus centralis; and (2) at the hindermost part of the lobus occipitalis. At the first place, when trying to separate it, a thin layer of the corticalis was torn off and adhered to the pia mater. At the second place was found an abseess, filled with thick pus, the size of a walnut; the corticalis was at this place partially destroyed, and it looked as if the abscess was formed in it with a thin layer of brain substance on its outer side; but it is possible that it might have been formed in the coverings only, lying between these and the brain. The pia mater was, on the whole, somewhat thickened, and the vessels filled. Along these was found on the convexity and the basis an aburdant purulent secretion, which also covered the middle brain, the cerebellum, and the medulla oblongata, being still more abun. dant here than over the cerebrum. The ventricles were moderately dilated with light-coloured, limpid serum. The tela choroidea was infiltrated with pus. The brain tissue was of normal consistence, not congested, excepting the places named under 1 and 2 . The medulla spinalis was covered with a similar purulent secretion as the brain, most abundant on the dorzal aspect. It was scarcer in the region of the neck and of the uppermost paris of the back than over the dorso-lumbar region and the cauda equina. The medulla spinalis itself was, macroscopically seen, normal. The pericardium, ear, pulmonis, larynx and trachea, the bronchial glands, cesophagus, ventriculus, peritoneum, intestina, mesenteric glands, hepar, spleen, reins, organa urinaria and generationis did not present abnormalities of any importance. Both osea temporis were taken out, and examined on July $12 \mathrm{th}$ and $13 \mathrm{th}, 1890$. The os temporis dextrum was normally shaped. The meatus auditorius externus did not present any abnormalities until the integumentum commune had been stripped off the mem. brana tympani, when the deeply injected mucosa was seen shining through the propria. The membrana tympani was entire. The pars cartilaginea tubæ was lined with a pale mucosa, and did not contain any inflammatory products. Haring removed the tegmen cavitalis tympani and tubx, these cavities, and also the antrum mastoideum, were seen filled with muco-pus; when this was blown away the mucosa appeared red, swollen, and deeply injected, both on the walls and on the ossicula. No diseased bone was found under the mucosa. The nerves in the porus acusticus internus were bathed in pus and their sheath deeply injected. In their mutual relation and consistence nothing appeared abnormal. With the chisel the canalis semicircularis superior was first opened; its lumen appeared entirely filled with a reddish, pulpy tissue, in which the membranous tube was not distinguishable. A small piece of the tissue was brought on the freezing apparatus, and recognised microscopically as consisting of connective tissue richly interspersed with round cells in fatty degeneration and blood-corpuscles. The other semicircular canals showed the same condition as the superior through their whole course. The vestibulum was laid open with chisel from above; before the last thin slice of the bony capsule was removed the contents of the vestibulum were seen shining through it with a reddish tint. The cavity of the vestibulum is filled with the same kind of tissue as was found in the semicircular canals, and neither the sacculus nor the utriculus was recognisable. The cochlea also was filled with a similar tissue, as the rest of the labyrinth. The nervus acusticus, with its ramus vestibuli and cochlea, and the nervus facialis were examined microscopically. In the peri- and endonenrium was found a very slight infiltration with round indefinable cells. The axis cylinders and the tubular membranes were well preserved, but as the specimens have not been stained, nothing can with certainty be said about the marrow; yet there appeared such a space between the axis cylinder and the tubular membrane that the nerves evi dently had not suffered from any pressure. The os temporis sinistrum was examined in a similar way, and showed the same pathological changes with the exception that the vestibulum contained some pus.

Remarks. - Which way did the inflammation in this case travel to reach the labyrinth ? Laterally to the labyrinth was found a suppurative otitis media, and medially a menin. gitis, with an abundant purulent secretion. The pain can not help us to answer this question. It appeared for the first time on the eleventh day of the disease, and was never con. siderable. Neither can the disordered function be our guide. It was observed on the tenth day. On the twelfth 
day the patient was very hard of hearing, and on the sixteenth day she became completely deaf, and remained so till her death. At that time we were justified in diagnosing a diseased labyrinth, as so complete a deafness would not be found with an otitis media ipcomplicata. Taking into account a series of necropsies upon patients who have died from many different kinds of disease, suffering from an otitis media suppurativa, without having been able by a macroscopical but diligent examination to see that the labyrinth had undergone any pathological change, and further, considering the abundant purulent secretion in the subdural space, whence the perilymphatic space of the labyrinth may be injected, while another road leads from it along the sheaths of the nerves directly to the membranous labyrinth, the conclusion seems to be that the inflam. mation had spread from the meningitis to the labyrinth. I have been surprised to see how little attention has been paid to the treatment in those cases of crebrospinal meningitis complicated with ear symptoms which I have come across. An inflammation as in the foregoing case would, it seems to me, indicate the applican tion of antiphlogistics and calomel, pushed so far as the condition of the patient would allow. To the readers of the Arch. $f$. Ohrenhk. the case will be of interest as representing the initial stage of the pathological changes found in a case published there this year by Dr. H. Mygind and myself, where the periostitis running through its different stages had resulted finally in the formation of bone, which entirely filled up the semicircular canals, and partially the vestibulum and cochlea, while the nervous acusticus had undergone a centripetal degenerative atrophy. The microscopical examination of the nerves in the porus acusticus internus revealed no pathological changes of any importance, although the disease had lasted forty-five daysevidence of the remarkable resistance of the nervous fibres against pathological influences.

\section{OTORRHEA, OR INFLAMMATION OF THE} MEATUS OF THE EAR.

BY J. SWIFT WALKER, M.D., F.R.C.S.EDIN.,

MEDICAL OFFICER OF HEALTH TO THE COUNTY BOROUGH OF HANLEY.

OTORRHCA is a word derived from ovs wTos, the ear; and jew, to flow. I do not like the word or its meaning. The disease or affection is an inflammation of the meatus, with a characteristic discharge denoting its origin; it only becomes "otorrhœa" when it has become "chronic," with perforation of the membrana tympani, called by many specialists "perforative otorrhoea," each variety requiring its special treatment, and in consequence of care not being taken to diagnose the characteristic variety of the discharge, the disease has become an opprobrium to most practitioners. The lengthened course of the disease is the main cause, however, of numbers of persons becoming deaf, besides the innumerable perforations of the membrana tympani, which may be seen by anyone who makes a specialty of ear affections. Now, in the first instance, there may be simple catarrh of the meatus with a muco-purulent discharge; what I would call an exanthematous inflam mation following scarlatina or some eruptive disease, a most virulent and destructive form of the affection; then tubercular otorrhoea, the tubercle bacillus being frequently found when properly searched for. Syphilitic otorrhoea was first described by Dr. Woakes. The diabetic ear, although so sudden in its attack and destructive, is really otitis media. Scrofulous inflammation is very intractable, but yields to specific combined with constitutional treatment; yet one without the other is of no utility. "Otorrhoea" really caused by otitis media, and discharging through a perforated tympanum, is not a discharge from the meatus, but exudes into the meatus, which shall be treated of as each variety of the disease is spoken of. The inflammation from dentition and stomach derangement in children is one of the simple varieties of the disease, yet one of the class most neglected by mothers, as they are under the impression that the discharge will cease without remedial measures-a most delusive impression, and one that it is the duty of every practitioner to endeavour to remove, asif allowed to go on it is certain to destroy the tympanum or cause perforation. Some practitioners use a disinfectant, and if one is used my preference for the ear is resorcin. I can refer to notes and find many cases where carbolic acid has been used with destructive changes. In my opinion nothing is more irritating to an inflamed meatus and tympanum than this preparation. Really no disinfectant is required until there is perforation of the drum, when the treatment will come under that heading. When the case becomes chronic, or an old neglected case comes under notice, it becomes a question whether the dry plan of treatment is to be preferred; if so, the following mode should be adopted. Take an ear probe. Dr. Macnaughton Jones has invented a very good one, but it is too light. Messrs. Krohne and Sesemann of Duke-street, Cavendish-square, make a splendid instrument, quite solid, with one end flat and serrated, for wrapping wool around, the other end is a corkscrew, which is very handy. I take a piece of wool, insert it in the meatus, press it down with the flat end of the probe, then take the other end, and with the corkscrew extract the wool. Again, this method clears the meatus without any pain of all discharge, which is a great desideratum. The first day disinfect the meatus with a little iodoform, infiated by Kabinsky's inflator; use on the second and following days with the following powder : Talc (creta (Gallica), three drachms; boric acid, one drachm. These powders require carefully mixing in a mortar; the boric acid cannot be rendered sufficiently fine without first being mixed with about one drachm of the tale, which when thoroughly pulverised is mixed with the remainder of the chalk. This is a very useful formula, and one that I have used for years. If this does not succeed at the end of a week I use creoline dusting powder. As for the sozoiodol preparations, I cannot say they have proved very useful in my hands. In the perforative variety of otorrhcea the same precautions are necessary in cleansing the meatus daily, but they cannot be treated on the dry plan. A good lotion is the following: Resorcin, half a scruple; extract of opium, one drachm; chloride of zinc, one grain ; water to one ounce and a half. A little to be syringed into the ear each morning.

In the treatment of the simplest variety of inflammation of the meatus in children nothing is so effective as a calomel purge, and a little belladonna and chloroform liniment, equal parts, smeared over the mastoid region to relieve the pain, which is sometimes very distressing. If it goes on further, and there is a mucous purulent discharge, wipe out the discharge daily with a little piece of wool wrapped round an ear probe, then paint the meatus with tannate of glycerine.

In exanthematous inflammation after any of the zymotic diseases, as scarlatina, measles, \&c., we come to a very intractable form of the affection, which requires great care and attention with perseverance. A very good lotion is alum iron, three drachms; sulphate of zine, two drachms water to eight ounces. First syringe out the ear with warm water, dry it thoroughly with cotton wool, so as to wipe out all discharge, then with the lotion. This must be done by the medical man; it is no good trusting the parents of children to do this thoroughly. I always use the preparation of iron, alum being so much more astringent than the potash or ammonia preparation, but in all these cases I find the great object is to see that the Eustachian tube is thoroughly open; either use a Politzer's bag or the catheter if necessary once a week. The syphilitic and tubercular otorrhœas must be treated upon the same principles, but with the addition of strict hygienic and constitutional treatment. Hanley.

DeRbY AND DERBYSHIRE INFIRMARY. - The annual meeting of the governors was held at the infirmary, Sir Wm. Evans, Bart., presiding. The chairman stated that the new buildings connected with the infirmary were now completed. Dr. Ogle intimated his approaching re. tirement from the medical staff, after thirty years' service, feeling incapable of devoting in the future, in the discharge of his duties, the same amount of time as he had done in the past. The statistics of in- and out-patients for the year showed a decrease of the former of 244 , and of the latter 9 , as compared with the previous year. The outpatient casualties numbered 1796, and the dental cases 890 The income, exclusive of legacies, amounted to $\$ 58555 \mathrm{~s} .10 \mathrm{~d}$. The report was adopted. 